Clinical implications of lumbar developmental spinal stenosis on back pain, leg pain and disability

Bone Joint J 2021;103-B(1):131-140, https://doi.org/10.1302/0301-620X.103B1.BJJ-2020-

1186.R2

1

\title{
2 ABSTRACT
}

\section{Background}

4 Lumbar developmental spinal stenosis (DSS) describes pre-existing narrowed spinal canal at 5 multiple lumbar levels $s_{2}$ which predisposes subjects to develop compressive symptoms easier.

6 However, the relationships between various MRI phenotypes and clinical outcomes are unclear. 7

\section{Objective}

9 To study the associations of demographics, lifestyle factors and different MRI phenotypes with 10 low back pain (LBP) and radiating leg [JK1]painradiculopathy.

\section{Methods}

13 This was a cross-sectional study of 2206 subjects with L1-S1 axial and sagittal magnetic 14 resonance imaging (MRI). Clinical and radiological information regarding subjects' demographics, workload, smoking habit, anteroposterior (AP) vertebral canal diameter,

16 Schmorl's nodes, spondylolisthesis, and other MRI phenotypes was assessed. Mann-Whitney

$17 U$ tests and Chi-square tests were conducted to search for differences between subjects with 18 and without DSS.[DS2] Associations of intensity of LBP and presence of radiating pain [JK3] teg

19 radiculopathy in the past month and the past year with the clinical and radiological information were also investigated by utilizing univariate and multivariate logistic regressions. 


\section{Results}

3 Subjects with DSS had more severe LBP intensity, higher prevalence of radiating leg_-pain

4 radiculopathy, more pain-related disability and lower quality of life (all $\mathrm{p}<0.05$ ). In addition, 5 subjects with spondylolisthesis had $1.5(95 \% \mathrm{CI}=1.0-2.3 ; \mathrm{p}=0.048)$ and $1.7(95 \% \mathrm{CI}=1.0-$ $63.0 ; \mathrm{p}=0.033$ ) times higher odds of experiencing LBP in the past month and the past year, 7 respectively. Individuals with DSS had $1.4(95 \% \mathrm{CI}=1.0-2.1 ; \mathrm{p}=0.048)$ and $1.8(95 \% \mathrm{CI}=$ 8 1.3-2.6; $\mathrm{p}=0.001)$ times higher odds of having radiating leg pain radiculopathy in the past 9 month and the past year ${ }_{2}$ respectively. Schmorl's nodes were also significantly associated with 10 leg radiculopathy in the past month $(\mathrm{OR}=1.5 ; 95 \% \mathrm{CI}=1.1-1.9 ; \mathrm{p}=0.006)$ and the past year $11 \quad(\mathrm{OR}=1.5 ; 95 \% \mathrm{CI}=1.2-2.0 ; \mathrm{p}=0.002)$

12

\section{Conclusion}

14 This is the first large-scale study that identified possible risk factors that were associated with 15 LBP and leg radiculopathy. Multilevel DSS, spondylolisthesis and Schmorl's nodes are 16 potential risk factors of acute and chronic pain. These MRI phenotypes should be assessed carefully in a clinical setting. 


\section{INTRODUCTION}

Low back pain (LBP) and leg radiculopathy are two of the most common health

3 problems around the world ${ }^{1-3}$. They bring about deterioration in one's quality of life, daily

4 disability, absence from work, mental health disturbance, and increased public health burden ${ }^{4-}$

$5 \quad{ }^{6}$. However, LBP is generally nonspecific ${ }^{7}$ and in these cases, the underlying cause is often

6 unrecognizable. One of the leading causes of these symptoms is compression of the nerve roots

7 in patients with stenotic lumbar canals ${ }^{8,9}$. Identification of their radiological phenotypes with

8 magnetic resonance imaging (MRI) is currently the gold standard ${ }^{10,11}$ and is imperative for

9 identifying the potential source of LBP or leg radiculopathy. Many MRI phenotypes are

10 postulated to be possible pain generators when studies investigated in their individual effects,

11 including dural sac cross-sectional $\mathrm{area}^{12}$, disc degeneration and herniation ${ }^{7,13,14}$, facet joint

12 degeneration $^{15}$, radial tears ${ }^{16}$, high intensity zone $(\mathrm{HIZ})^{17}$, and Modic changes ${ }^{18,19}$.

13 In addition to soft tissue changes, lumbar developmental spinal stenosis (DSS) may

14 also play an important role in causing pain. Having a prevalence of $7.3 \%^{20}$, it is suggested that

15 DSS is not an uncommon pathology in the Chinese population. DSS is described as pre-existing

16 narrowed vertebral canals at multiple lumbar levels ${ }^{21-23}$. It is an important factor to consider in

17 spinal stenosis surgery as patients with DSS have a high reoperation rate of up to $22 \%^{23-25}$. A

18 large amount of studies focused on defining DSS radiologically ${ }^{22,26-31}$, but only a few

19 investigated its clinical course and clinical presentation ${ }^{9,32}$. Subjects with DSS are found to

20 have earlier onset of symptoms during their fourth or fifth decades ${ }^{33}$ as mild degenerative

21 changes of the lumbar spine are already sufficient to compress the neural elements. Although

22 DSS and other MRI phenotypes were observed to be closely related, their interactions in

23 causing pain are still poorly understood. The contribution of DSS in generating pain alone is

24 also unknown. Furthermore, there is little consensus on what radiological abnormalities of the

25 lumbar spine contribute most to LBP, leg pain or disability. Systematic reviews by Brinjikji et 
$1 a l^{34,35}$ commented that high proportions (>29\%) of asymptomatic subjects had some abnormal

2 changes of the spine although they were less prevalent than among patients with LBP.

Therefore, this study was designed to address the aforementioned incomprehensive understanding on the interaction of DSS and different MRI phenotypes in producing different clinical outcomes namely LBP, leg radiculopathy and disability.

6

7 METHODS

Study Design and Population

This was a cross-sectional large-scale study of 2206 Chinese subjects from the Hong

10 Kong Disc Degeneration Cohort Study ${ }^{17,22,26,36-38}$. All subjects were openly recruited via

11 newspapers advertisement, posters and e-mails, regardless of their social and economic status.

12 Participants with prior surgical treatment of the spine, spinal tumours, and marked spinal

13 deformities were excluded from the study. Subjects selected were not based on the presence or

14 absence of clinical symptoms. All qualified subjects underwent T1-weighted axial MRI and

15 T2-weighted sagittal MRI of the lumbosacral spine (L1-S1) after informed consent was

16 obtained from participants and ethics was approved by a local institutional board.

Low Back Pain and Leg Radiculopathy

Information related to LBP and leg radiculopathy was recorded as follows: age of onset, any pain experienced in the past month (30 days) and the past year (365 days). LBP was defined as pain localizing in the lower back and/or buttocks. Leg radiculopathy was defined as pain

22 radiating from the lower back/buttocks to one or both lower extremities beyond the knee in a

23 dermatomal pattern that may be associated with numbness and paresthesia ${ }^{39}$ [JK4]. Visual analog

24 scale (VAS) was utilized to measure the worst LBP experience since the day of onset. The 
1 severity of LBP was subdivided into 3 categories according to previously published criteria ${ }^{17,40}$ : no or mild pain (VAS < 3), moderate pain (VAS $3-5.9$ ), and severe pain (VAS $\geq 6$ ).

\section{Lifestyle Factors and Disability}

Age, gender, height and weight were obtained on the day with MRI. Body mass index (BMI) was calculated by weight/height ${ }^{2}\left(\mathrm{~kg} / \mathrm{m}^{2}\right)$. Information on previous lumbar spine injury, smoking habit, regular exercise and occupation was surveyed. Previous lumbar spine injury was a closed-ended question for subjects to recall any prior back injury regardless of severity. Occupation was characterized into different subgroups based on the physical workloads ${ }^{17,19}: 1$ $=$ sedentary work (lifting $10 \mathrm{lbs}$ ); $2=$ light work (lifting $20 \mathrm{lbs}$ ); 3 = medium work (lifting 50 lbs); 4 = heavy or very heavy work (lifting $\geq 100 \mathrm{lbs}$ ). Pain-related disability was assessed by the Oswestry Disability Index (ODI) ${ }^{41}$ and the Roland Morris Disability Questionnaire $(\mathrm{RMQ})^{42}$. Quality of life was assessed by the 36-Item Short Form Survey (SF-36) ${ }^{43}$. An ODI of $\geq 15 \%$ was noted as pain-related disability ${ }^{40}$.

\section{MRI Protocol}

1.5T or 3T HD_MRI [DS5]machines were used for axial and sagittal imaging at L1-S1. Subjects were oriented in the supine position. For T1-weighted axial scans, the field of view was $21 \mathrm{~cm} \times 21 \mathrm{~cm}$, slice thickness was $4 \mathrm{~mm}$, slice spacing was $0.4 \mathrm{~mm}$, and imaging matrix was $218 \times 256$. For T2-weighted sagittal scans, the field of view was $28 \mathrm{~cm} \times 28 \mathrm{~cm}$, slice thickness was $5 \mathrm{~mm}$, slice spacing was $1 \mathrm{~mm}$, and imaging matrix was $448 \times 336$. The repetition time for T1- and T2-weighted MRI were 500ms-800ms and 3320ms respectively, and their echo time was $9.5 \mathrm{~ms}$ and $85 \mathrm{~ms}$. According to the pedicle and disc levels, 11 parallel slices were made at each spinal level. The MRI protocol has been described in further details elsewhere ${ }^{22}$. 


\section{MRI Measurements[DS6]}

Two independent investigators were blinded to all demographical and clinical data before and during MRI measurements. Methodologies on obtaining the measurements were aligned before the assessment. Forty MRI films were randomly selected by a third independent investigator for repeated measurements which were at least 4 weeks after the initial measurements. This data was used to assess the intraobserver and interobserver reliability.

The cut with the thickest pedicle diameter, pedicle, lamina and vertebral body was utilized for every T1-weighted axial MRI. The following measurements were obtained for L1S1 axial MRI: anteroposterior (AP) vertebral canal diameter (Figure 1) and left and right facet joint angle (Figure 2). Facet joint angle was the angle made by a line joining the corners of the facet joint and the transverse plane. Facet joint angulation of greater than $58^{\circ}$ at L4-L5 was regarded as abnormal ${ }^{44}$. Facet joint tropism was noted if the absolute difference between left and right facet joint angle was greater than 8 degrees based on the definition by Samartzis et $\underline{a l}^{44}$.

T2-weighted sagittal MRI was acquired at the midsagittal cut with the most prominent lumbar spinous processes. The following measurements were obtained for L1-S1: presence of disc herniation, disc degeneration ${ }^{45}$, Schmorl's nodes $^{46}$ (Figure 3), endplate irregularity, [DS7]high intensity zone (HIZ) $)^{17,47}$ (Figure 4), radial tear, spondylolisthesis (Figure 4), Modic change and anterior marrow change ${ }^{48}$. Disc herniation was further divided into 4 categories: $0=$ no disc herniation; 1 = posterior disc bulging (disc displaced beyond a virtual line connecting the posterior edges of two adjacent vertebrae); 2 = disc extrusion (distance between the edge of the protruded disc into the spinal canal was greater than the distance between edges of the base of the disc); $3=$ disc sequestration ${ }^{17,18,49}$. The scores of each lumbar level were added up as disc herniation score and further categorized into two subgroups ${ }^{17}$ : disc herniation score of $<2$ (no or mild disc herniation) and disc herniation score of $\geq 3$ (moderate to several disc herniation). 
1 Disc degeneration was evaluated using the Pfirrmann grading ${ }^{45}: 1=$ homogeneous bright white

2 disc; 2 = inhomogeneous white disc and/or horizontal bands; 3 = inhomogeneous grey disc; 4

3 = inhomogeneous grey to black disc; $5=$ inhomogeneous black disc. The scores of each lumbar

4 level were added up as disc degeneration score and further categorized into two subgroups:

5 disc degeneration score of $<16$ (no or mild disc degeneration) and disc degeneration score of

$6 \geq 16$ (moderate to severe disc degeneration) ${ }^{50}$. Schmorl's node was defined as herniation of the

7 nucleus pulposus into the adjacent vertebral body. [DS8]Endplate irregularity was described as an

8 irregular surface at the endplates. [DS9]HIZ was defined as a high-intensity area of the anterior or

9 posterior annulus fibrosus ${ }^{17,51,52}$. Radial tear was noted as a hyperintense line in the annulus

10 fibrosus. Spondylolisthesis was characterized by anterior displacement of the cranial vertebral

11 body on the caudal vertebra. Modic change was described as high-signal intensity change

12 involving the whole or middle posterior of the vertebral body adjacent to the endplates, while

13 anterior marrow change was described as high-signal intensity change at the anterior vertebral

14 body adjacent to the endplates. The presence of Schmorl's nodes, endplate irregularity, HIZ,

15 radial tear, spondylolisthesis, Modic change and anterior marrow change were defined as one

16 or more radiological findings of their respective entities throughout the entire lumbar spine.

17 Dichotomizing these variables are more relevant to a clinical setting.

Definition of Lumbar Developmental Spinal Stenosis

Subjects were noted to have multilevel DSS if their axial AP vertebral canal diameters

21 were below the proposed cut-offs at 3 or more lumbosacral levels ${ }^{20}: \mathrm{L} 1<19 \mathrm{~mm}, \mathrm{~L} 2<19 \mathrm{~mm}$,

$22 \mathrm{~L} 3<18 \mathrm{~mm}, \mathrm{~L} 4<18 \mathrm{~mm}, \mathrm{~L} 5<18 \mathrm{~mm}, \mathrm{~S} 1<16 \mathrm{~mm}$. This criterion was utilized as it recognizes the

23 importance of multilevel stenosis in patients with DSS.

Statistical Analysis 
Frequency and descriptive statistics were performed for all variables. Normality testing was performed. For detecting differences between DSS and non-DSS subjects, Mann-Whitney

$3 U$ tests were performed for continuous independent variables including age, BMI, average 4 mean ODI, mean average RMQ, mean average SF-36, axial AP vertebral canal diameter, and

5 left and right facet joint angle, while chi-square tests were used for categorical independent

6 variables including gender, previous spinal injury, smoking habit, regular exercise, physical

7 workload, LBP within the past month and the past year, LBP intensity, leg radiculopathy within

8 the past month and the past year, pain-related disability, abnormal left and right facet joint

9 angulation, facet joint tropism, disc herniation score, disc degeneration score, presence of

10 Schmorl's nodes, endplate irregularity, HIZ, radial tear, spondylolisthesis, Modic change, and

11 anterior marrow change. Means and ranges were also calculated for all T1-weighted axial MRI

12 measurements. Intraobserver and interobserver reliability assessments were based on Cronbach

$13 \alpha$ analysis: $\alpha$ values of 0.90 to 1.00 was noted to have excellent reliability; $\alpha$ values of 0.80 to

140.89 was noted to have good reliability ${ }^{53}$.

15 Univariate logistic regressions were then conducted to detect any association between individual independent variables and clinical outcomes (LBP in the past month and the past

17 year, and leg radiculopathy in the past month and the past year). All demographics, lifestyle

18 factors and MRI measurements except AP vertebral canal diameter were included as

19 independent variables as it was used to dichotomize subjects into DSS and non-DSS. Variables

20 that were statistically significant $(\mathrm{p}<0.05)$ in the univariate logistic regressions were included

21 to build four multivariate logistic regression models based on the four clinical outcomes (LBP

22 in past month and year, and leg radiculopathy in past month and year), after controlling for age,

23 gender, and BMI. These[DS10] models were used to assess the association of lifestyle factors together

24 with MRI phenotypes with LBP and leg radiculopathy [JK11] experienced in the past month and the

25 past year. As no published article demonstrated the best prediction equation in a similar 
1 situation, stepwise regression was used in these models to explore for possible impactful factors.

2 Adjusted odds ratios (OR) and 95\% confidence interval (CI) were obtained from these models. A P-value of less than 0.05 was considered as statistically significant. All statistical analyses were performed by SPSS Statistics 26 (IBM SPSS Inc., Chicago, Illinois).

\section{RESULTS}

Among 2206 subjects, 153 were identified to have multilevel DSS. Descriptive and

8 frequency statistics in subjects with and without multilevel DSS were presented in Table 1 and

9 Table 2. Excellent interobserver $(\alpha=0.90-0.96)$ and intraobserver reliability $(\alpha=0.92-0.99$

10 and $\alpha=0.92-0.99$ ) between the two independent investigators were noted. Associations of

11 multilevel DSS with demographics, lifestyle factors, and MRI phenotypes were also presented.

12 Subjects with multilevel DSS were noted to have narrower spinal canals and more likely to be

13 females (75.8\%). They also have higher VAS which inferred more severe pain, higher

14 incidence of leg radiculopathy both in past month and past year, higher average ODI, RMQ,

15 and higher physical component score in SF-36. In addition, abnormal right facet joint

16 angulation, higher disc herniation score and higher disc degeneration score were associated

17 with multilevel DSS.

18 Table 3 showed the results of the univariate logistic regressions on LBP. Statistically

19 significant associations of LBP in the past month with previous lumbar injury and

20 spondylolisthesis were observed. These independent variables were used to conduct a

21 multivariate logistic regression analysis (Table 4) which reached statistical significance (Chi

22 square $(5, \mathrm{n}=2160)=185.911 ; \mathrm{p}<0.001)$. After adjusting for gender, age and BMI, subjects

23 with previous lumbar injury (adjusted $\mathrm{OR}=3.663 ; 95 \% \mathrm{CI}=2.994-4.480$ [DS12] $\mathrm{p}<0.001$ ) and

24 spondylolisthesis (adjusted $\mathrm{OR}=1.526 ; 95 \% \mathrm{CI}=1.004-2.322$ [DS13]; $\mathrm{p}=0.048$ ) had higher odds of

25 LBP in the past month. 
Age, previous lumbar injury, and spondylolisthesis were associated with LBP in the

2 past year (Table 3). These independent variables were used to conduct a multivariate logistic 3 regression analysis (Table 4$)$ which reached statistical significance (Chi square $(5, n=2163)=$ 4 220.918; $\mathrm{p}<0.001$ ). After adjusting for gender, age and BMI, subjects with previous lumbar 5 injury (adjusted $\mathrm{OR}=5.627 ; 95 \% \mathrm{CI}=4.291-7.380 ; \mathrm{p}<0.001)$ and spondylolisthesis (adjusted $6 \quad \mathrm{OR}=1.762 ; 95 \% \mathrm{CI}=1.047-2.963 ; \mathrm{p}=0.033)$ had higher odds of LBP in the past month.

7 Similarly, Table 5 showed the results of the univariate analyses on leg radiculopathy.

8 Gender, age, BMI, previous lumbar injury, workload, multilevel DSS, and Schmorl's nodes 9 were associated with leg radiculopathy in the past month. These independent variables were 10 included in a multivariate logistic regression analysis (Table 6) which reached statistical 11 significance (Chi square $(9, \mathrm{n}=2209)=157.899, \mathrm{p}<0.001)$. After adjusting for gender, age and BMI, subjects with previous lumbar injury (adjusted $\mathrm{OR}=2.715 ; 95 \% \mathrm{CI}=2.231-3.303$; $\mathrm{p}<0.001$ ), heavy workload (adjusted $\mathrm{OR}=1.743 ; 95 \% \mathrm{CI}=1.053-2.887 ; \mathrm{p}=0.031$ ), multilevel 14 DSS (adjusted OR $=1.439 ; 95 \% \mathrm{CI}=1.004-2.063 ; \mathrm{p}=0.048$ ) and Schmorl's nodes (adjusted $15 \mathrm{OR}=1.458 ; 95 \% \mathrm{CI}=1.113-1.911 ; \mathrm{p}=0.006)$ had higher odds of leg radiculopathy in the past 16 month.

Gender, age, BMI, previous lumbar injury, multilevel DSS, and Schmorl's nodes were associated with leg radiculopathy in the past year (Table 5). Table 6 shows the results of the multivariate logistic regression analysis of these significant independent variables with leg radiculopathy in the past year, which reached statistical significance (Chi square $(9, \mathrm{n}=2088)$ $21=170.615, \mathrm{p}<0.001)$. After adjusting for gender, age and BMI, subjects with previous lumbar injury (adjusted $\mathrm{OR}=2.714 ; 95 \% \mathrm{CI}=2.243-3.284 ; \mathrm{p}<0.001$ ), multilevel DSS (adjusted OR

$23=1.811 ; 95 \% \mathrm{CI}=1.262-2.600 ; \mathrm{p}=0.001)$ and Schmorl's nodes $($ adjusted $\mathrm{OR}=1.510 ; 95 \% \mathrm{CI}$ $24=1.158-1.970 ; \mathrm{p}=0.002$ ) had higher odds of leg radiculopathy in the past month. If the 
1 significant factors were removed from the above models, their effects were shown by the

2 changes in $-2 \log$ likelihood (all $\mathrm{p}<0.05)$.

\section{DISCUSSION}

LBP and leg radiculopathy are common health conditions that one may experience

6 during his/her lifetime. It is observed that the periphery of the annulus fibrosus and endplates

7 are highly innervated, while the nucleus pulposus and inner annulus fibrosus of the disc are

8 free of innervation ${ }^{54,55}$. Pain is generated when the intact structure of the vertebral disc is

9 disrupted or when nociceptors are stimulated by compression. However, these clinical

10 presentations are often poorly associated with the imaging profiles, except for HIZ and Modic

11 changes which are relatively well-documented ${ }^{51,56}$. In addition, patients with multilevel DSS

12 have pre-existing narrowed vertebral canals which predisposed them to a lower threshold of

13 neural compression. This was further proven by our results which showed these subjects were

14 associated with a shorter AP vertebral canal diameter at L1-S1 $(\mathrm{p}<0.001)$. They may experience

15 LBP and leg radiculopathy even if a milder degree of degenerative changes of the lumbar spine

16 is present. Yet, to date, there is no research on their interactions in causing pain. The contribution of multilevel DSS in generating pain is also unknown. Therefore, our study was the first to show that subjects with spondylolisthesis had higher risks of LBP in the past month and the past year, while subjects with multilevel DSS and Schmorl's nodes had higher risks of

20 leg radiculopathy in the past month and the past year.

We compared the clinical outcomes in subjects with and without multilevel DSS. The former group had more severe LBP $(\mathrm{p}=0.013)$ and higher prevalence of leg radiculopathy in the past month $(\mathrm{p}=0.008)$ and the past year $(\mathrm{p}=0.001)$. This might be attributed to the narrowed spinal canal that causes the subject more prone to nerve root compression, leading to pain radiating to the legs. However, LBP was not found to be significantly different between 
1 the two groups even though nerve root compression could also lead to LBP. This could be due

2 to its nonspecific characteristics ${ }^{7,57}$. LBP can be caused by many other pathologies such as

3 intervertebral disc disruption, facet joint and sacroiliac joint disruption, ligament or muscle

4 strain, and idiopathic causes. A clinical study by Dai et $a l^{8}$ examining the preoperative clinical

5 symptoms in patients with DSS also realized more patients experienced leg radiculopathy or

6 sciatica than LBP. Furthermore, this group was also associated with higher pain-related

7 disability scores (ODI and RMQ) and lower quality of life (SF-36), specifically for the physical

8 component score. Similarly, Lee et $\mathrm{al}^{58}$ observed the majority of the patients with DSS

9 undergoing surgery had lower quality of life and poorer clinical presentation including more

10 severe and incapacitating pain, shorter walking distance, poorer sitting endurance, and muscle

11 weaknesses. It was also found that subjects with DSS were more prone to disc herniation and

12 disc degeneration, as suggested by their higher scores. Although statistically significant, the

13 absolute differences between groups were small and might not be clinically relevant.

14 Pain lasting for less than 6 weeks is defined as acute, while pain lasting for more than

1512 weeks is noted to be chronic ${ }^{59}$. Our large-scale study was able to obtain this clinical 16 information for both LBP and leg radiculopathy. The predicting variables appeared to be the

17 same in both LBP in the past month and the past year, but subjects with spondylolisthesis were

18 found to have a higher risk of having LBP for a longer period of time after adjusting for

19 demographic confounders (adjusted $\mathrm{OR}=1.762 ; 95 \% \mathrm{CI}=1.047-2.963$ ). Among all of its

20 etiologies, degeneration is the most common form of spondylolisthesis seen in adults ${ }^{60}$. Acute

21 causes such as trauma could also lead to fractures and dislocation at the posterior elements, but

22 this is more likely in a children cohort ${ }^{61}$. Therefore, chronic pain is more likely to be found in

23 these patients. [DS14] Our findings are also supported by a meta-analysis of 28 articles consisting of

2426,107 subjects conducted by Raastad et $a l^{62}$. They noticed significant association between 
1 spondylolisthesis and LBP in both occupational-based studies $(\mathrm{OR}=2.21 ; 95 \% \mathrm{CI}=1.44-3.39)$

2 and community-based studies $(\mathrm{OR}=1.12 ; 95 \% \mathrm{CI}=1.03-1.23)$.

3 On the other hand, subjects with leg radiculopathy were associated with older age, 4 larger BMI, [DS15] and they were more likely to be females. Predictor variables were also found to be

5 the same for both leg radiculopathy in the past month and the past year. After adjusting for 6 demographics, subjects with multilevel DSS and subjects with Schmorl's nodes had higher 7 risks of having chronic leg radiculopathy compared to acute leg radiculopathy. Our 8 multivariate analysis was consistent with the results in Table 1 and this could be attributed to 9 the developmental origin of DSS, as the canal size is reported to be unchanged after puberty 10 and skeletal maturity ${ }^{33}$, and hence subjects with narrower spinal canals are more likely to 11 experience nerve roots compression and lead to chronic pain. Furthermore, Schmorl's nodes were found to be associated with leg radiculopathy. However, this is poorly documented in current literature and is more likely to be associated with $\mathrm{LBP}^{46}$ as Schmorl's node locates in

14 the disc-vertebral junction without affecting the spinal canal. Scatter researches ${ }^{63}$ reported 15 radicular pain in patients with Schmorl's nodes as the only radiological finding but they are of 16 low level of evidence. Schmorl's node [DS16]is possibly a result of maldevelopment of the vertebrae which is similar to DSS ${ }^{64}$. Patients with DSS are more likely to have Schmorl's nodes $(15.7 \%$ vs $13.2 \%)$ although it is found to be statistically insignificant $(P=0.386)$ in our study. This might be influenced by our small sample size $(n=24)$ in those who had both DSS and

20 Schmorl's nodes. However, this association is still preliminary and require future longitudinal 21 studies to justify. Nevertheless, multilevel DSS is more likely to be a significant risk factor in causing nerve root compression and leg radiculopathy.

Some relatively well-documented associations of clinical outcomes with MRI 24 phenotypes such as Modic changes ${ }^{56}$ and $\mathrm{HIZ}^{17}$ were found to be insignificant in this study. 25 The methodologies in those studies were different from our study as they examined the 
1 individual effect of the MRI phenotypes on pain. In contrast, our study attempted to search for

2 possible predictors that contributed to generating pain by covering the majority of MRI

3 phenotypes that are commonly seen in the population. Due to these considerations, our study

4 is the first to integrate demographics with lifestyle factors and MRI phenotypes and examine

5 their relationship with clinical outcomes. [DS17]

6 There are several limitations to this study. Firstly, our results may not be generalizable

7 in other ethnicities as only Chinese subjects were recruited. However, this is beneficial to the

8 strength of exploration as it limits potential unknown confounders between ethnic groups.

9 Secondly, as with other cross-sectional studies, we cannot conclude any causative relationships

10 between the independent variables and clinical outcomes. Thirdly, as subjects were openly

11 recruited via advertisements, the proportion of males and females were not equally distributed.

12 [DS18]In addition, this method of sampling subjects may not be representative of the true population

13 as individuals who respond to advertisements may be inherently biased. It will be useful to

14 follow-up these subjects to observe the impact of lifestyle factors and MRI phenotypes on

15 clinical outcomes in the long run. Changes in intensity of pain across time is also of interest to

16 understand the complete picture.

\section{CONCLUSION}

This is the first large-scale study that examined the associations of lifestyle factors,

20 DSS, and different MRI phenotypes with LBP and leg radiculopathy. Our study observed that

21 subjects with spondylolisthesis had higher likelihoodrisks of LBP [JK19]in the past month and the past year, while subjects with multilevel DSS and Schmorl's nodes had higher likelihoodrisks

23 of leg radiculopathy in the past month and the past year. These should be assessed carefully in

24 a clinical setting. Future longitudinal studies are necessary to understand the associations 
1 between different phenotypes and pain, and to observe the changes in clinical presentation over 2 time. 
3 1. Andersson GB. Epidemiology of low back pain. Acta Orthop Scand Suppl $1998 ; 281: 28-31$.

2. Deyo RA, Cherkin D, Conrad D, Volinn E. Cost, controversy, crisis: low back pain and the health of the public. Annu Rev Public Health 1991;12:141-156.

3. Stafford MA, Peng P, Hill DA. Sciatica: a review of history, epidemiology, pathogenesis, and the role of epidural steroid injection in management. Br J Anaesth 2007;99:461-473.

4. Dieleman JL, Baral R, Birger M, et al. US Spending on Personal Health Care and Public Health, 1996-2013. JAMA 2016;316:2627-2646.

5. Hoy D, March L, Brooks P, et al. The global burden of low back pain: estimates from the Global Burden of Disease 2010 study. Ann Rheum Dis 2014;73:968-974.

6. Vos T, Flaxman AD, Naghavi M, et al. Years lived with disability (YLDs) for 1160 sequelae of 289 diseases and injuries 1990-2010: a systematic analysis for the Global

7. DePalma MJ, Ketchum JM, Saullo T. What is the source of chronic low back pain

8. Dai LY, Ni B, Jia LS, Liu HK. Lumbar disc herniation in patients with developmental spinal stenosis. Eur Spine J 1996;5:308-311.

9. Verbiest H. Results of surgical treatment of idiopathic developmental stenosis of the lumbar vertebral canal. A review of twenty-seven years' experience. J Bone Joint Surg Br 1977;59:181-188.

10. Herzog RJ, Guyer RD, Graham-Smith A, Simmons ED, Jr. Magnetic resonance imaging. Use in patients with low back or radicular pain. Spine (Phila Pa 1976) 1995;20:1834-1838. 
1 11. Modic MT, Ross JS. Magnetic resonance imaging in the evaluation of low back pain. The Orthopedic clinics of North America 1991;22:283-301.

3 12. Iwahashi H, Yoshimura N, Hashizume H, et al. The Association between the Cross-Sectional Area of the Dural Sac and Low Back Pain in a Large Population: The Wakayama Spine Study. PLoS One 2016;11:e0160002.

13. Schwarzer AC, Aprill CN, Derby R, Fortin J, Kine G, Bogduk N. The prevalence and clinical features of internal disc disruption in patients with chronic low back pain.

14. Samartzis D, Borthakur A, Belfer I, et al. Novel diagnostic and prognostic methods

15. Cavanaugh JM, Ozaktay AC, Yamashita T, Avramov A, Getchell TV, King AI. Mechanisms of low back pain: a neurophysiologic and neuroanatomic study. Clin Orthop Relat Res 1997:166-180.

16. Videman T, Nurminen M. The occurrence of anular tears and their relation to lifetime back pain history: a cadaveric study using barium sulfate discography. Spine (Phila Pa 1976) 2004;29:2668-2676.

17. Teraguchi M, Cheung JPY, Karppinen J, et al. Lumbar high-intensity zones on

18. Maatta JH, Karppinen JI, Luk KD, Cheung KM, Samartzis D. Phenotype profiling of Modic changes of the lumbar spine and its association with other MRI phenotypes: a large-scale population-based study. The spine journal : official journal of the North American Spine Society 2015;15:1933-1942. 
1 19. Mok FP, Samartzis D, Karppinen J, Fong DY, Luk KD, Cheung KM. Modic changes of the lumbar spine: prevalence, risk factors, and association with disc degeneration and low back pain in a large-scale population-based cohort. The spine journal : official journal of the North American Spine Society 2016;16:32-41.

20. Lai MKL, Cheung PWH, Samartzis D, Cheung JPY. Prevalence and definition of multilevel lumbar developmental spinal stenosis. Spine [Under Review].

21. Verbiest H. A radicular syndrome from developmental narrowing of the lumbar vertebral canal. J Bone Joint Surg Br 1954;36-B:230-237.

22. Cheung JP, Samartzis D, Shigematsu H, Cheung KM. Defining clinically relevant values for developmental spinal stenosis: a large-scale magnetic resonance imaging study. Spine (Phila Pa 1976) 2014;39:1067-1076.

23. Cheung PWH, Fong HK, Wong CS, Cheung JPY. The influence of developmental spinal stenosis on the risk of re-operation on an adjacent segment after decompression-only surgery for lumbar spinal stenosis. Bone Joint J 2019;101-B:154161.

24. Machado GC, Ferreira PH, Harris IA, et al. Effectiveness of surgery for lumbar spinal stenosis: a systematic review and meta-analysis. PLoS One 2015;10:e122800.

25. Javalkar V, Cardenas R, Tawfik TA, et al. Reoperations after surgery for lumbar spinal stenosis. World Neurosurg 2011;75:737-742.

26. Cheung JPY, Ng KKM, Cheung PWH, Samartzis D, Cheung KMC. Radiographic indices for lumbar developmental spinal stenosis. Scoliosis Spinal Disord 2017;12:3.

27. Chatha DS, Schweitzer ME. MRI criteria of developmental lumbar spinal stenosis revisited. Bulletin of the NYU hospital for joint diseases 2011;69:303-307.

28. Kitab SA, Alsulaiman AM, Benzel EC. Anatomic radiological variations in developmental lumbar spinal stenosis: a prospective, control-matched comparative 
analysis. The spine journal : official journal of the North American Spine Society 2014;14:808-815.

29. Alicioglu B, Yilmaz B, Bulakbasi N, et al. Magnetic resonance imaging predictors of surgical outcome in degenerative lumbar spinal stenosis. Jpn J Radiol 2012;30:811-818.

30. Kitab S, Habboub G, Abdulkareem SB, Alimidhatti MB, Benzel E. Redefining lumbar spinal stenosis as a developmental syndrome: does age matter? J Neurosurg Spine 2019;31:357-365.

31. Kitab S, Lee BS, Benzel EC. Redefining lumbar spinal stenosis as a developmental syndrome: an MRI-based multivariate analysis of findings in 709 patients throughout the 16- to 82-year age spectrum. J Neurosurg Spine 2018;29:654-660.

32. Reale F, Delfini R, Gambacorta D, Cantore GP. Congenital stenosis of lumbar spinal canal: comparison of results of surgical treatment for this and other causes of lumbar syndrome. Acta Neurochir(Wien) 1978;42:199-207.

33. Kim KH, Park JY, Kuh SU, Chin DK, Kim KS, Cho YE. Changes in spinal canal diameter and vertebral body height with age. Yonsei Med J 2013;54:1498-1504.

34. Brinjikji W, Luetmer PH, Comstock B, et al. Systematic literature review of imaging features of spinal degeneration in asymptomatic populations. AJNR Am J Neuroradiol 2015;36:811-816.

35. Brinjikji W, Diehn FE, Jarvik JG, et al. MRI Findings of Disc Degeneration are More Prevalent in Adults with Low Back Pain than in Asymptomatic Controls: A Systematic Review and Meta-Analysis. AJNR Am J Neuroradiol 2015;36:2394-2399.

36. Cheung KM, Samartzis D, Karppinen J, Luk KD. Are "patterns" of lumbar disc degeneration associated with low back pain?: new insights based on skipped level disc pathology. Spine (Phila Pa 1976) 2012;37:E430-438. 
1 37. Mok FP, Samartzis D, Karppinen J, Luk KD, Fong DY, Cheung KM. ISSLS prize winner: prevalence, determinants, and association of Schmorl nodes of the lumbar spine with disc degeneration: a population-based study of 2449 individuals. Spine (Phila Pa 1976) 2010;35:1944-1952.

38. Samartzis D, Karppinen J, Chan D, Luk KD, Cheung KM. The association of lumbar intervertebral disc degeneration on magnetic resonance imaging with body mass index in overweight and obese adults: a population-based study. Arthritis and rheumatism 2012;64:1488-1496.

39. Koes BW, van Tulder MW, Peul WC. Diagnosis and treatment of sciatica. BMJ 2007;334:1313-1317.

40. Maatta JH, Karppinen J, Paananen M, et al. Refined Phenotyping of Modic Changes: Imaging Biomarkers of Prolonged Severe Low Back Pain and Disability. Medicine (Baltimore) 2016;95:e3495.

41. Fairbank JC, Pynsent PB. The Oswestry Disability Index. Spine (Phila Pa 1976) 2000;25:2940-2952; discussion 2952.

42. Stratford PW, Binkley J, Solomon P, Finch E, Gill C, Moreland J. Defining the minimum level of detectable change for the Roland-Morris questionnaire. Phys Ther 1996;76:359-365; discussion 366-358.

43. JE W, KK S, M K, B G. SF-36 Health Survey Manual and Interpretation Guide. Boston. Massachusetts: New England Medical Center. The Health Institute 1993.

44. Samartzis D, Cheung JP, Rajasekaran S, et al. Critical Values of Facet Joint Angulation and Tropism in the Development of Lumbar Degenerative Spondylolisthesis: An International, Large-Scale Multicenter Study by the AOSpine Asia Pacific Research Collaboration Consortium. Global Spine J 2016;6:414-421. 
1 45. Pfirrmann CW, Metzdorf A, Zanetti M, Hodler J, Boos N. Magnetic resonance classification of lumbar intervertebral disc degeneration. Spine (Phila Pa 1976) 2001;26:1873-1878.

46. Kyere KA, Than KD, Wang AC, et al. Schmorl's nodes. Eur Spine J 2012;21:21152121.

47. Aprill C, Bogduk N. High-intensity zone: a diagnostic sign of painful lumbar disc on magnetic resonance imaging. Br J Radiol 1992;65:361-369.

48. Modic MT, Steinberg PM, Ross JS, Masaryk TJ, Carter JR. Degenerative disk disease: assessment of changes in vertebral body marrow with MR imaging. Radiology 1988;166:193-199.

49. Cheung KM, Karppinen J, Chan D, et al. Prevalence and pattern of lumbar magnetic resonance imaging changes in a population study of one thousand fortythree individuals. Spine (Phila Pa 1976) 2009;34:934-940.

50. Boden SD, Davis DO, Dina TS, Patronas NJ, Wiesel SW. Abnormal magneticresonance scans of the lumbar spine in asymptomatic subjects. A prospective investigation. J Bone Joint Surg Am 1990;72:403-408.

51. Teraguchi M, Yim R, Cheung JP, Samartzis D. The association of high-intensity zones on MRI and low back pain: a systematic review. Scoliosis Spinal Disord 2018;13:22.

52. Teraguchi M, Samartzis D, Hashizume H, et al. Classification of High Intensity Zones of the Lumbar Spine and Their Association with Other Spinal MRI Phenotypes: The Wakayama Spine Study. PLoS One 2016;11:e0160111.

53. Vangeneugden T, Laenen A, Geys H, Renard D, Molenberghs G. Applying concepts of generalizability theory on clinical trial data to investigate sources of variation and their impact on reliability. Biometrics 2005;61:295-304. 
1 54. Fagan A, Moore R, Vernon Roberts B, Blumbergs P, Fraser R. ISSLS prize winner: The innervation of the intervertebral disc: a quantitative analysis. Spine (Phila Pa 1976) 2003;28:2570-2576.

55. Palmgren T, Gronblad M, Virri J, Kaapa E, Karaharju E. An immunohistochemical study of nerve structures in the anulus fibrosus of human normal lumbar intervertebral discs. Spine (Phila Pa 1976) 1999;24:2075-2079.

56. Herlin C, Kjaer P, Espeland A, et al. Modic changes-Their associations with low back pain and activity limitation: A systematic literature review and meta-analysis. PLoS One 2018;13:e200677.

57. Chenot JF, Greitemann B, Kladny B, Petzke F, Pfingsten M, Schorr SG. NonSpecific Low Back Pain. Dtsch Arztebl Int 2017;114:883-890.

58. Lee CK, Hansen HT, Weiss AB. Developmental lumbar spinal stenosis. Pathology and surgical treatment. Spine (Phila Pa 1976) 1978;3:246-255.

59. Patrick N, Emanski E, Knaub MA. Acute and chronic low back pain. Med Clin North Am 2014;98:777-789, xii.

60. Eismont FJ, Norton RP, Hirsch BP. Surgical management of lumbar degenerative spondylolisthesis. J Am Acad Orthop Surg 2014;22:203-213.

61. Ibebuike K, Roussot M, Watt J, Dunn R. Management challenges of traumatic spondylolisthesis of the Axis with an unusual C2-C3 posterior subluxation in a paediatric patient: case report and literature review. Afr Health Sci 2018;18:458-467.

62. Raastad J, Reiman M, Coeytaux R, Ledbetter L, Goode AP. The association between lumbar spine radiographic features and low back pain: a systematic review and meta-analysis. Semin Arthritis Rheum 2015;44:571-585.

63. Kim S, Jang S. [Radicular pain caused by Schmorl's node: a case report]. Rev Bras Anestesiol 2018;68:322-324. 
1 64. Samartzis D, Mok FPS, Karppinen J, Fong DYT, Luk KDK, Cheung KMC. Classification of Schmorl's nodes of the lumbar spine and association with disc degeneration: a large-scale population-based MRI study. Osteoarthritis Cartilage 2016;24:1753-1760.

5

6 


\section{FIGURE LEGENDS}

2 Figure 1. Axial magnetic resonance imaging measurement: (A) anteroposterior (AP) vertebral 3 body diameter.

4 Figure 2. Axial magnetic resonance imaging measurement: (B) left and right facet joint angle 5 (made by a line joining the corners of the facet joint and the transverse plane).

6 Figure 3. Sagittal magnetic resonance imaging: (C) Schmorl's nodes (herniation of the nucleus 7 pulposus into the adjacent vertebral body).

8 Figure 4. Sagittal magnetic resonance imaging: (D) High intensity zones (high-intensity area

9 of the anterior or posterior annulus fibrosus); (E) Spondylolisthesis (anterior displacement of 10 the cranial vertebral body on the caudal vertebra). 